\title{
Preparation of Bioactive Coatings on the Surface of Bioinert Polymers through an Innovative Auto-Catalytic Electroless Route
}

\author{
J.M. Oliveira ${ }^{1,2, a}$, I.B. Leonor ${ }^{1,2, b}$ and R.L. Reis ${ }^{1,2, c}$ \\ 1 3B's Research Group Biomaterials, Biodegradables and Biomimetics, University of Minho, \\ Campus Gualtar, 4710-057 Braga, Portugal \\ ${ }^{2}$ Department of Polymer Engineering, University of Minho, Campus Azurém, 4810-058 Guimarães, \\ Portugal \\ amiguel.oliveira@dep.uminho.pt, bbelinha@dep.uminho.pt, 'crgreis@dep.uminho.pt
}

Keywords: Apatite, Auto-Catalytic, Bioactivity, Biodegradable, Coating, Polymers

\begin{abstract}
The aim of this research was to develop a new methodology to obtain bioactive coatings on bioinert and biodegradable polymers that are not intrinsically bioactive. In this study, three types of materials were used as substrates: (i) high molecular weight polyethylene (HMWPE) and two different types of starch based blends (ii) starch/ethylene vinyl alcohol blends, SEVA-C, and (iii) starch/cellulose acetate blends, SCA. These materials were obtained by injection moulding and by extrusion with blowing agents in order to obtain compact/porous 3D architectures. Three types of baths were developed in order to produce the newly proposed auto-catalytic Ca-P coatings: (i) alkaline, (ii) acid, and (iii) oxidant bath. The obtained results indicated that it was possible to coat the materials surfaces with calcium phosphate (Ca-P) layer with only $60 \mathrm{~min}$ of immersion in the different types of auto-catalytic solutions. These innovative auto-catalytic electroless route allows for the production of an adherent bioactive film on the polymeric surfaces. Furthermore, it was possible observe by SEM/EDS the clear bioactive nature of the Ca-P coatings after different immersion periods, in a simulated body fluid (SBF).
\end{abstract}

\section{Introduction}

Several polymeric materials are bioinert, i.e. that are typically encapsulated by a fibrous tissue when implanted in the body due to the impossibility to occur the formation per-si of an apatite layer on their surface [1]. Therefore, great attention has been given to the surface modification of polymers in attempt to obtain a bioactive surface [2]. These are known to have great efficacy in promoting a stronger bone-implant bonding in vivo [3]. However, one constraint arises from the possibility of producing a Ca-P coating weakly bond to the substrate which can loose the strength rapidly when exposed to the physiological environment. Reis et al. [4] have been studing new autocatalytic deposition methodologies to produce Ca-P coatings which possess good adhesion, and allow for controlling the $\mathrm{Ca}$ and $\mathrm{P}$ composition and its cristallinity. The main aim of this work is to optimise the operation parameters by studying the bath composition and adequate coating conditions, in an attempt, to further control the morphology and microstructure of the "electroless" coatings, as well as its adhesion to the bioinert and biodegradable polymers that are not intrinsically bioactive.

\section{Materials and Methods}

In this study three types of materials were used, namelly: (i) A high molecular weight polyethylene (HMWPE), and two different types of starch based biomaterials: (ii) starch/ethylene vinyl alcohol blends (SEVA-C 30/50\%wt), and (iii) starch/cellulose acetate blends (SCA 50/50\%wt). These materials were prepared by conventional injection moulding process and by extrusion with blowing agent. In order to produce bioactive coating the samples were soaked in three different baths for 60 min with continuously agitated by a magnetic stirrer: (i) alkaline, (ii) acid, and (iii) oxidant bath. 
The respective compositions and typical operating conditions for each bath are shown in the Table 1.

Afterwards, the substrates were soaked into simulated body fluid (SBF), with an ion compositiom similar to those found in human body, for several periods up to 30 days, in order to evaluate the bioactivity of the coatings. After soaking, the specimens were immediately cleaned with distilled water and dried at $23{ }^{\circ} \mathrm{C}$ under a constant relative humidity of $55 \%$. The specimens were analysed by scanning electron microscopy with an attached energy dispersive electron probe X-ray analyser (SEM/EDS), thin-film X-ray diffraction (TF-XRD), and Fourier transform attenuated total reflectance infrared spectroscopy (FTIR-ATR). The evolution of $\mathrm{Ca}$ and $\mathrm{P}$ concentrations was determined as function of time by induced-coupled plasma emission (ICP) spectroscopy.

Table 1 - Bath compositions and operating conditions for electroless Ca-P films

\begin{tabular}{|c|c|c|c|}
\hline Bath & Composition (conc. g/L) & pH adjust. & Bath Temp. $\left({ }^{\circ} \mathrm{C}\right)$ \\
\hline Alkaline & $\begin{array}{l}\text { Calcium chloride }\left(\mathrm{CaCl}_{2}\right)-5.6 \\
\text { Sodium hypophosphite }\left(\mathrm{NaH}_{2} \mathrm{PO}_{2} \cdot \mathrm{H}_{2} \mathrm{O}\right)-21 \\
\text { Sodium pyrophosphate }\left(\mathrm{NaP}_{2} \mathrm{O}_{7} \cdot 10 \mathrm{H}_{2} \mathrm{O}\right)-6.7 \\
\text { Palladium chloride }\left(\mathrm{PdCl}_{2}\right)-0.9\end{array}$ & $\mathrm{NaOH}-9.2$ & $60{ }^{\circ} \mathrm{C}$ \\
\hline Acid & $\begin{array}{l}\text { Calcium chloride }\left(\mathrm{CaCl}_{2}\right)-5.6 \\
\text { Sodium hypophosphite }\left(\mathrm{NaH}_{2} \mathrm{PO}_{2} \cdot \mathrm{H}_{2} \mathrm{O}\right)-24 \\
\text { Ortho-phosphoric }\left(\mathrm{H}_{3} \mathrm{PO}_{4}\right)-3.4 \\
\text { Palladium chloride }\left(\mathrm{PdCl}_{2}\right)-0.9 \\
\text { Sodium fluoride }(\mathrm{NaF})-5.0\end{array}$ & $\mathrm{HCl}-5.3$ & 80 \\
\hline Oxidant & $\begin{array}{l}\text { Calcium chloride }\left(\mathrm{CaCl}_{2}\right)-5.6 \\
\text { Sodium pyrophosphate }\left(\mathrm{NaP}_{2} \mathrm{O}_{7} .10 \mathrm{H}_{2} \mathrm{O}\right)-6.7 \\
\text { Palladium chloride }\left(\mathrm{PdCl}_{2}\right)-0.9 \\
\text { Oxygen peroxide }\left(\mathrm{H}_{2} \mathrm{O}_{2}\right)-34.0\end{array}$ & 7.0 & 60 \\
\hline
\end{tabular}

\section{Results and Discussion}

By means of using the innovative auto-catalytic deposition methodology it was possible to coat all materials surfaces with a Ca-P layer after only $60 \mathrm{~min}$ of immersion, as it is shown in the Figures 1 , 2 and 3. These results once, confirmed the previous ones by means of using this autocatalytic deposition route showed to be very promissing to produce Ca-P coatings on the surface of different bioinert polymers [4]. Moreover, this layer could be also observed inside the pores, clearing covering the cell walls (Fig. 2 and 3). From the characterization of the coatings generated by the three types of baths, it was found that morphologies of the Ca-P deposited on different substrates are quite distinct. In fact, it was possible to observe that the acid coating (that typically operates at $80{ }^{\circ} \mathrm{C}$ ) generates a film with a more pronounced needle-like morphology, than the alkaline and oxidant coatings (that typically operates at $60^{\circ} \mathrm{C}$ ) (Figure 1 and 2). These differences are probably related with the fact that the operation temperature of the acid bath is usually higher than of the alkaline bath which help to maintain a higher deposition rate.

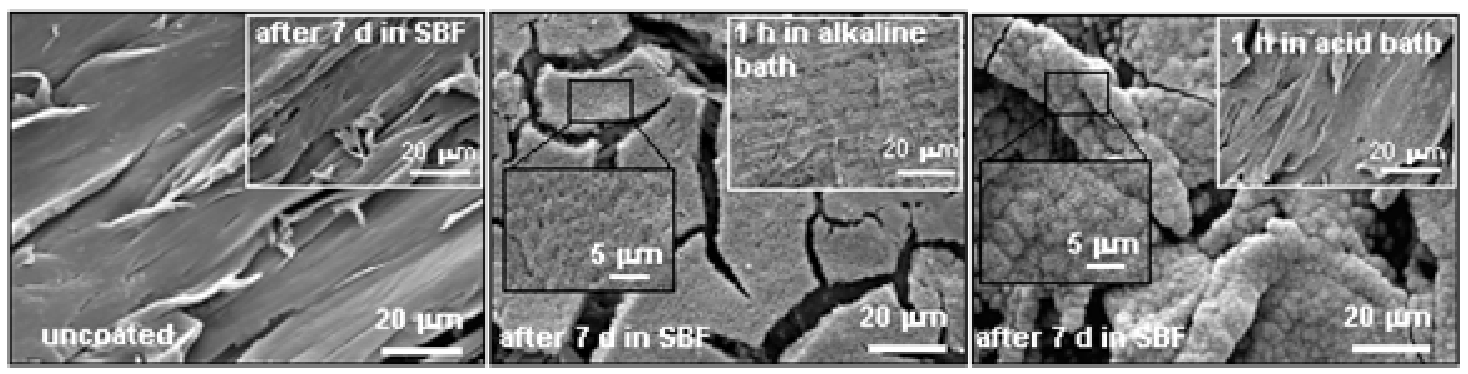

Figure 1. SEM images of the surface HMWPE uncoated, and after $1 \mathrm{~h}$ in the alkaline and acid bath, followed by soaking in SBF solution for 7 days. 


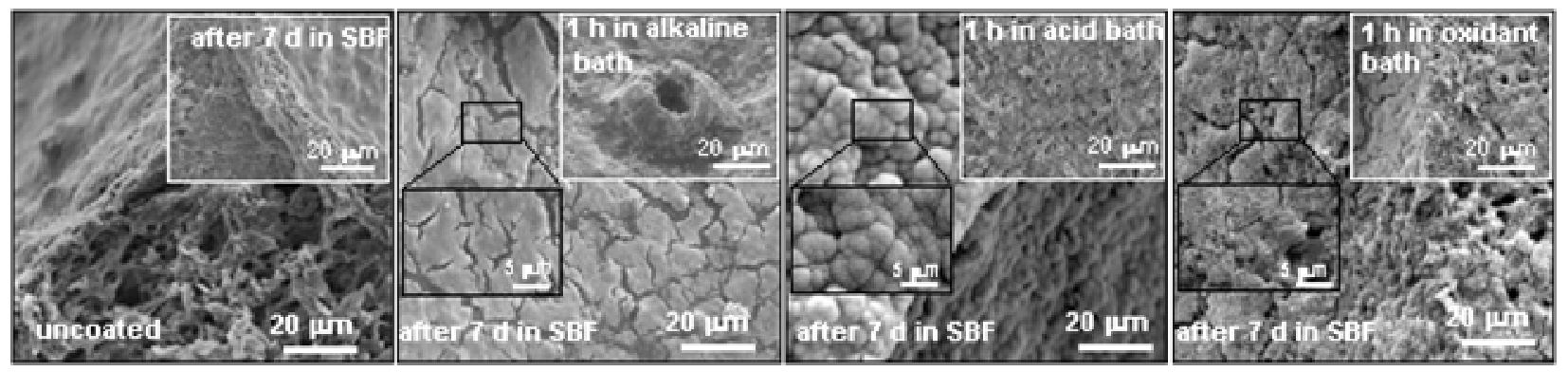

Figure 2. SEM images of the surface SEVA-C uncoated and after $1 \mathrm{~h}$ in the alkaline, acid and oxidant bath, and subsequent soaking in SBF solution for 7 days.
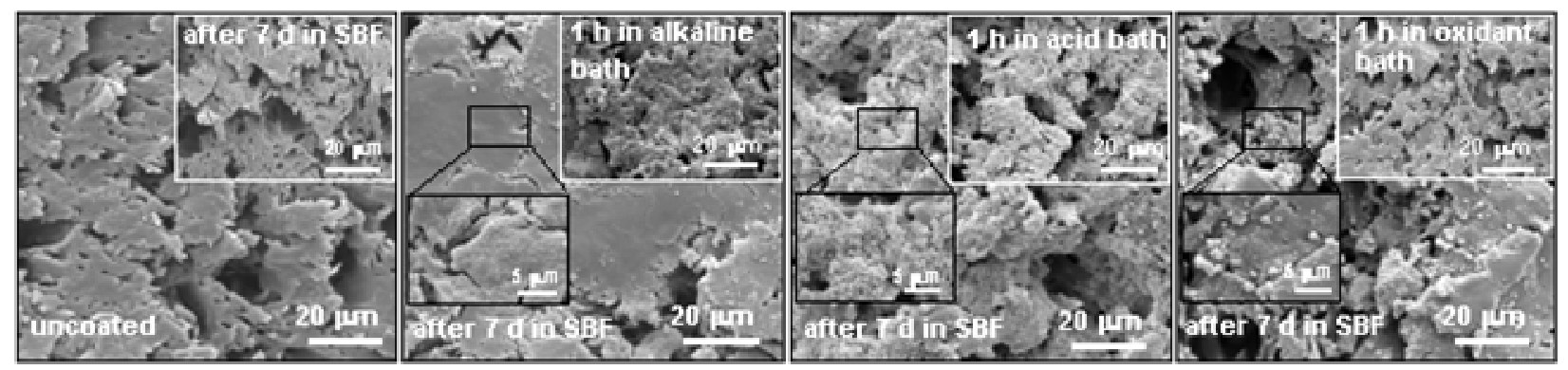

Figure 3. SEM images of the surface SCA uncoated and after $1 \mathrm{~h}$ in the alkaline, acid and oxidant bath, and subsequent soaking in SBF solution for 7 days.

Furthermore, between the substrates there is some considerable differences which were attributed to the polymer (SEVA-C, SCA) water uptake capability (as compare to bioinert HMWPE), which allowed the material to absorb higher quantities of $\mathrm{Ca}^{2+}$ and $\mathrm{PO}_{4}{ }^{3-}$ ions from the auto-catalytic "electroless" solutions when immersed. Besides, it can be seen that the morphology of the film obtained for SEVA-C, when immersed in the acid bath was clearly different from the obtained for SCA substrate. This observation may be explained by the different nature of the materials surface properties which influences its degradation rate. As previouly reported by Reis et al. [5], SCA materials underwent higher height losses in an isotonic saline solution, when compared with those for SEVA-C. Therefore, it is expected that the degree of adsorption of the different ions or transport across the interface apatite/solution phenomenoms, which are involved in the formation of an apatite layer, by the different substrates to modulate in a different extent the nucleation of the apatite layer. Similar findings for other materials, have been reported [6]. For the HMWPE substrate, the results obtained might be attributed to the absence of the polar groups on HMWPE substrate, which are known to have a significant role on the induction of the apatite nucleation [7]. By means of using the auto-catalytic baths it was possible to effectivelly promote the apatite nucleation in shorter periods of time.

For the scaffolds, it can be seen that the Ca-P layer is also observed inside the pores, clearing covering the cell walls (Figure 2 and 3). At higher magnifications it was possible to observe the morphology of this film that evidenced a finer structure, where the needle like crystals are agglomerated to produce the so-called cauliflower-like morphology as it is shown in the Figure 2. As for the uncoated sample, there is no formation of a Ca-P film as detected by the EDS spectra (Figure 4A).

The EDS spectra of all coatings after soaking in SBF show the calcium (Ca) and phosphorus (P) signal as typically shown in Figure 4B). In the particular case of the substrates treated with the acid bath, the XRD analysis of these coatings after immersion in SBF for different periods evidenced the existence of the characteristic main peaks of apatite, which match the standard pattern of hydroxyapatite (data not shown). Therefore, these results clearly shown that the change in the $\mathrm{Ca} / \mathrm{P}$ ratio of the auto-catalytic baths affected the calcium-phosphate crystal phases. 
The obtained results indicated that it was possible to coat the materials surfaces with a more cristalline calcium phosphate (Ca-P) layer. This layer exhibits a needle-like morphology on all the different substrates, including HMWPE, after 7 days in SBF. Thus, this innovative methodology demonstrated that it is possible to reduce the induction period for the apatite formation with only $60 \mathrm{~min}$ of immersion on the auto-catalytic baths.

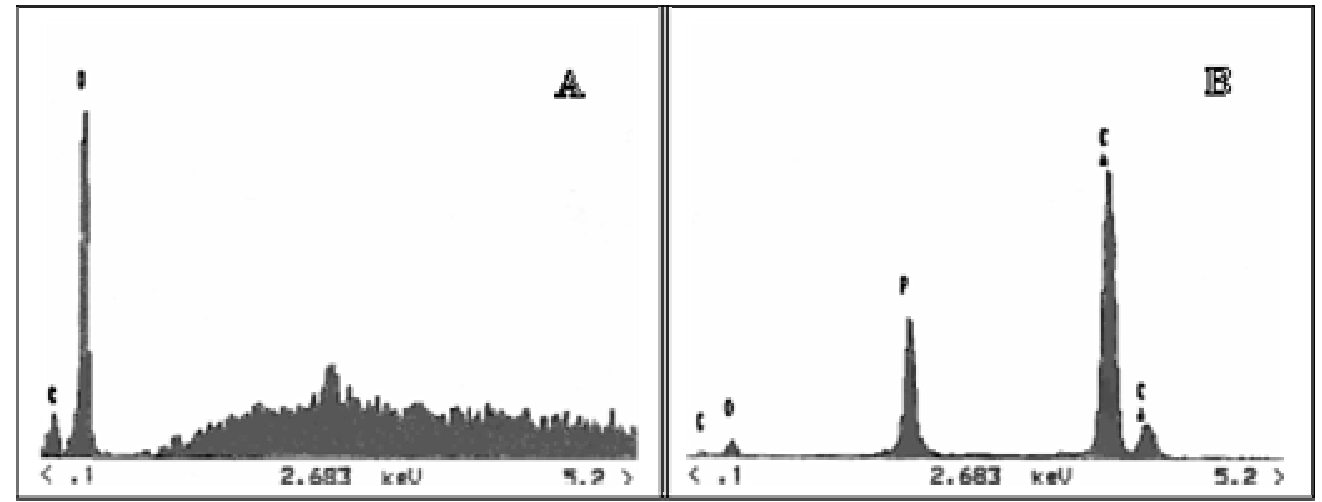

Figure 4. EDS spectra of the HMWPE surface: (A) uncoated after immersion for 7 days in SBF, and (B) after $1 \mathrm{~h}$ in the acid bath followed by immersion for 7 days in SBF.

\section{Conclusions}

By means of using an auto-catalytic deposition methodology it was possible to produce a Ca-P film on the surface of three types of polymers, polyethylene (HMWPE), and two types of starch based polymers (SCA and SEVA-C). Also, for the porous 3D architectures, the cell walls of the porous could be completely covered.

Additionally, these results showed that by means of using these auto-catalytic baths it was possible not only to reduce the induction period for the apatite nucleation but also to produce an adherent bioactive film on bioinert polymeric surfaces. The application of auto-catalytic coatings, prior to implantation, on these materials may allow for them to be used as bioactive tissue replacement materials and as bioactive tissue engineering scaffolds. Further work will investigate the cell adhesion and proliferation on the developed Ca-P auto-catalytic coatings.

\section{Acknowledgments}

I. B. Leonor thanks the Portuguese Foundation for Science and Technology for providing her a PhD scholarship (SFRH / BD / 9031 / 2002). This work was partially supported by FCT Foundation for Science and Technology, through funds from the POCTI and/or FEDER programmes.

\section{References}

[1] I.B. Leonor, R.A. Sousa, A.M. Cunha and R.L. Reis: J. Mater. Sci.: Mater. Med. Vol.13 (2002), pp. 939-945.

[2] T. Kokubo: Acta Mater. Vol. 46 (1998), pp. 2519-2527.

[3] T. Kokubo: J. Non-Cryst. Sol. Vol. 120 (1990), pp. 138.

[4] I.B. Leonor and R.L. Reis: J. Mater. Sci.: Mater. Med. Vol.14 (2003), pp. 435-441.

[5] M.E. Gomes, A.S. Ribeiro, P.B. Malafaya, R.L. Reis and A.M. Cunha: Biomater. Vol.22 (2001), pp. 883-889.

[6] J. Nyvlt, O. Söhnel, M. Matuchová and M. Broul (Elsevier Science Publishers, Netherlands 1985), p.24. 
[7] K. Hata, T. Kokubo, T. Nakamura and T. Yamamuro: J. Am. Ceram. Soc. Vol. 77 (1994), pp. 1049. 